\title{
Macromolecular templates for the development of organic/inorganic hybrid materials
}

\author{
Tatsuya Nishimura
}

Biominerals and the formation mechanisms of these materials have been studied intensively for decades. Biominerals have attracted much attention from material scientists because these compounds have significant mechanical and optical properties because of their elaborate structures. We believe that novel functional hybrid materials with hierarchical structures are best prepared using abundant elements and mild conditions, similar to the formation of natural biominerals. This review focuses on using an organic (bio)polymer for the formation of these hybrid materials based on $\mathrm{CaCO}_{3}$ and on understanding the formation of new hybrid materials via bio-inspired approaches. The structure-function relationships of biomineralization-related proteins are discussed. Molecular designs to control the properties of the hybrid materials are also described. The combination of experimentation and molecular simulation is also introduced. These studies provide useful ideas for the development of hybrid materials through biomimetic approaches.

Polymer Journal (2015) 47, 235-243; doi:10.1038/pj.2014.107; published online 17 December 2014

\section{INTRODUCTION}

The hard tissues of living organisms such as teeth, bone, seashells and the exoskeletons of crayfish are called biominerals. ${ }^{1-4}$ These materials are polymer/inorganic hybrid composites formed under mild conditions by molecularly controlled processes. ${ }^{1-4}$ Owing to the hierarchical structures of biominerals at the molecular level, these materials exhibit significant mechanical, ${ }^{5,6}$ optical ${ }^{7,8}$ and magnetic properties, ${ }^{9}$ which are exploited by the biomineral-producing organisms for a variety of purposes. It is known that biomacromolecules are essential for the formation of biominerals. In the process of biomineralization, wellordered macromolecular templates are first formed via selforganization and are then subsequently used as substrates for inorganic crystallization. ${ }^{10}$ The chemical and physical properties of biominerals, such as polymorphs, morphology, crystallographic orientation and crystal size, are strongly influenced by these templates. ${ }^{11}$ Biomineralization has inspired material scientists in the design of novel functional hybrid materials for several decades. ${ }^{12-19}$ Understanding the process of biomineral formation, and especially the roles of biomacromolecules in this process, is crucial to the development of new approaches to practical engineering processes. Although many studies on biomineralization-inspired crystallization and biomimetic hybrids have been reported, precisely controlled molecular processes for synthesizing hybrid materials under mild conditions have not yet been successfully achieved.

Kato and co-workers ${ }^{20-33}$ have conducted studies on polymer/ $\mathrm{CaCO}_{3}$ hybrid materials, especially thin-film hybrids, using biomineralization-inspired methods (Figure 1). The use of cooperative interactions between soluble and insoluble polymer matrices is essential for the formation of polymer/ $/ \mathrm{CaCO}_{3}$ hybrids. The production of thin-film hybrids containing both polymer and $\mathrm{CaCO}_{3}$ with a wide variety of morphologies, including flat, ${ }^{20-23,29}$ patterned, ${ }^{24,25,27,30}$ unidirectionally oriented $^{31-33}$ and threedimensional complex ${ }^{26,28}$ structures, was achieved by changing the combination of polymer templates used in the hybrid formation. For example, photoimaged patterns on $\mathrm{CaCO}_{3}$ thin films have been obtained by incorporating a combination of photo-crosslinkable polymer gel matrices and poly(acrylic acid) (PAA) additive into the hybrid material. ${ }^{27}$ Thin films of hydroxyapatite crystals have also been prepared on chitosan matrices in the presence of PAA. ${ }^{34}$ These results indicate that the use of polymer templates is crucial for controlling the formation of hybrid materials. Although intensive work regarding functional hybrids has been conducted over the decades, the study of functional hybrid production via the use of a macromolecular template has only just begun. Detailed formation mechanisms and appropriate molecular designs are still unclear.

This paper provides a review of the recent advances in understanding biomineralization processes and the development of new organic/ $\mathrm{CaCO}_{3}$ hybrids through biomineralization-inspired approaches. Three topics are reviewed in this paper, as described below: (1) The isolation of biomineralization-related peptides from living organisms and the roles of these peptides in the $\mathrm{CaCO}_{3}$ mineralization process are examined. The structure-function relationships of the peptides are discussed. (2) The spontaneous formation of macroscopically oriented crystals on oriented chitin matrices that were prepared via liquid crystalline assembly is presented. (3) $\mathrm{CaCO}_{3}$ hybrids have also been developed using amorphous mineral precursors, resulting in the formation of two- or three-dimensional composites. In the context of the above topics, the roles of the 


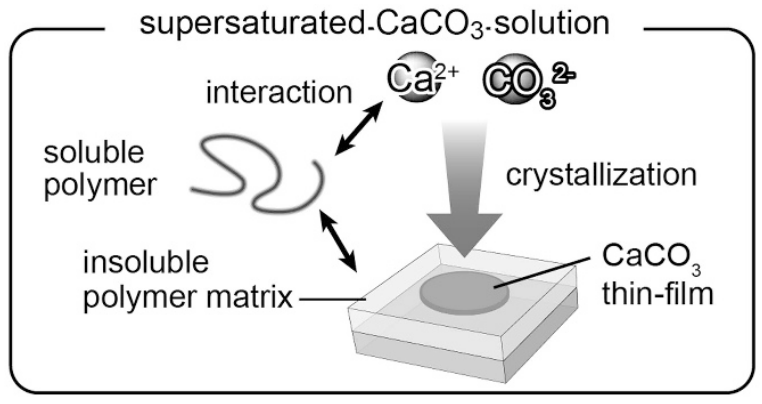

Figure 1 Schematic illustration of the formation of thin-film $\mathrm{CaCO}_{3}$.

macromolecular templates that affect the formation of novel polymer $/ \mathrm{CaCO}_{3}$ hybrid materials prepared via approaches inspired by biomineralization are reviewed in this paper.

\section{STUDIES OF THE STRUCTURE-FUNCTION RELATIONSHIPS OF BIOMINERALIZATION-RELATED PEPTIDES}

To date, the organic matrices of the nacre of seashells have attracted much attention because these biomacromolecules have a significant influence on the quality, including the color and luster, of pearls. ${ }^{35} \mathrm{In}$ 1960, Watabe and Wilbur ${ }^{36}$ reported for the first time the effects of organic matrices on $\mathrm{CaCO}_{3}$ crystallization. The organic matrices used were extracted from the nacre of a seashell. These authors demonstrated the formation of aragonite in the presence of organic matrices in vitro; aragonite is one of the polymorphs of $\mathrm{CaCO}_{3}$ found in the nacre layer. Generally, it is difficult to obtain aragonite in test tubes without the use of additives. The results indicated that polymorph control was achieved by the molecular control provided by the organic matrices. However, the researchers were not able to isolate the peptides critical for this process from the crude organic matrices because of limitations in peptide analysis at that time. More recently, owing to advances in biotechnology, several principal peptides have been isolated from the nacre of seashells with reverse-phase highpressure liquid chromatography and sodium dodecyl sulfatepolyacrylamide gel electrophoresis, and the chemical structures of these peptides have been identified. Nacrein was the first protein isolated from a nacre layer by Miyamoto et al., ${ }^{37}$ and this protein functions as a carbonic anhydrase to produce bicarbonate ions. Nacrein also interacts with $\mathrm{CaCO}_{3}$ through its acidic amino-acid residues. Thereafter, many other proteins, including $\mathrm{N} 14,{ }^{38} \mathrm{~N} 16,{ }^{39}$ MSI60, ${ }^{40}$ MSI7, ${ }^{41}$ pearlin, ${ }^{42}$ prismalin- $14,{ }^{43}$ perlucin ${ }^{44}$ and lustrin $\mathrm{A},{ }^{45}$ were successfully isolated from various mollusk shells. Some of the effects of these proteins on in vitro crystallization were also examined. It was found that these proteins interact with $\mathrm{CaCO}_{3}$ and have effects on the crystallization of $\mathrm{CaCO}_{3}$. However, no aragonite nucleation was observed in the presence of these proteins in vitro. It was believed that major proteins might be essential for the formation of the nacre layer. Although these major proteins have been isolated, the formation mechanism is still unclear.

Recently, Suzuki et al. ${ }^{46}$ isolated the matrix proteins Pif80 and Pif97 from the pearl oyster Pinctada fucata, as shown in Figure 2. They searched for aragonite-specific binding proteins using an aragonitebinding assay to identify the aragonite-inducing proteins. These investigators found that the novel protein Pif80, an $80 \mathrm{kDa}$ protein, specifically interacts with geological aragonite crystal surfaces. Pif80 is an Asp-rich acidic protein that forms an in vivo complex through disulfide bonds with Pif97, an additional peptide that is posttranslationally cleaved from a precursor protein (Figure 2a). It was also found

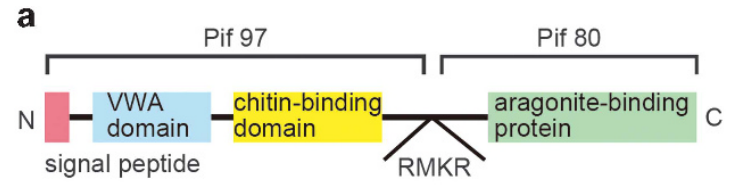

b
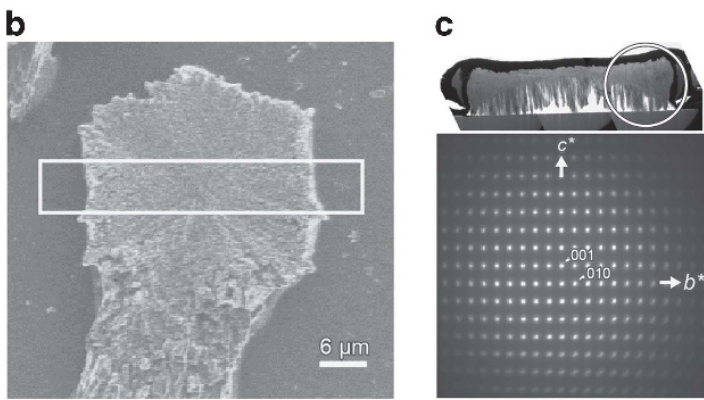

d

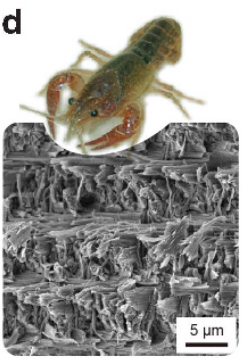

f

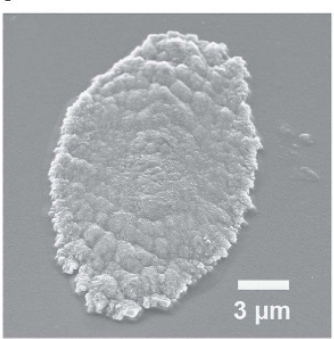

e

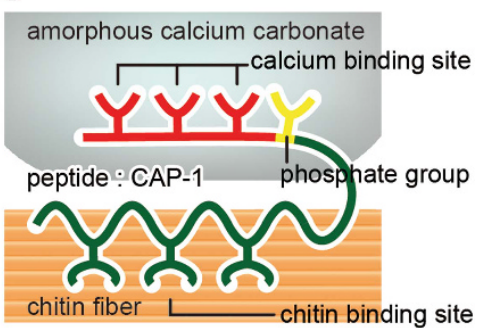

g

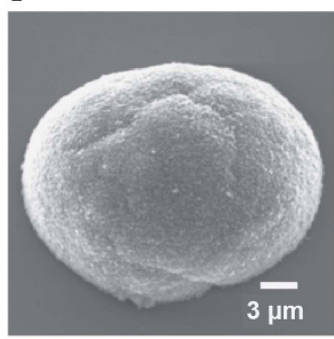

Figure 2 (a) Schematic illustration of the protein structure of the Pif complex. Boxes represent the signal peptide, the VWA domain and the peritrophin A-type chitin-binding domain. RMKR is a Kex2-like proteinase cleavage site. The right box is the aragonite-binding protein (Pif80). (b) $\mathrm{CaCO}_{3}$ crystal observed with scanning electron microscopy (SEM). (c) Electron diffraction pattern in a cross-section of the white circled area of the white box in (b). (d) SEM image of a crayfish exoskeleton. (e) Schematic illustration of CAP-1 in the exoskeleton structure. SEM images of $\mathrm{CaCO}_{3}$ formed on (f) chitin and ( $g$ ) a glass substrate in the presence of CAP-1 $\left(2.4 \times 10^{-3} w t \%\right)$. Reproduced with permission from the reference.

that Pif80 has an aragonite-binding domain and Pif97 has chitinbinding domains, both of which are acidic, with pI (isoelectric point) values of 4.99 and 4.65 , respectively. Suzuki et al. ${ }^{46}$ also found that the Pif complex acts at the interface between the organic layer and the aragonite tablets via the complex's binding domains and regulates the formation of the nacre layers. The in vitro conditions of the crystallization of $\mathrm{CaCO}_{3}$ in the presence of the Pif complex were examined by using $\mathrm{CaCO}_{3}$ supersaturated solution ${ }^{21}$ to understand how the Pif complex assists in this process. Notably, the Pif complex induces aragonite thin-film growth with the $\mathrm{c}$ axis aligned perpendicular to the surface of a chitin matrix, as observed for natural nacre (Figures $2 \mathrm{~b}$ and $\mathrm{c}$ ). These results confirmed that the Pif complex is essential for nacre formation. This study also revealed that the biomineralizationrelated proteins are able to control the process of biomineral 
formation even when present in tiny amounts. Moreover, each step in the functional sequence, such as the $\mathrm{CaCO}_{3}$ - and chitin-binding steps, might be connected to one another to maximize the efficiency of the formation process.

The exoskeletons of crustaceans are one of the most extensively studied types of biominerals that are composed of $\mathrm{CaCO}_{3}$ and biomacromolecules. ${ }^{4-49}$ Figure $2 \mathrm{~d}$ shows the fractured surface of the exoskeleton of a crayfish. The hierarchical composite structure of the chitin fibrils arranged in a helical array along with amorphous $\mathrm{CaCO}_{3}$ (ACC) can be observed. Owing to their elaborate structures, exoskeletons have excellent mechanical properties, such as ductility and toughness, while also being lightweight. This structure is similar to that of fiber-reinforced plastics, and material scientists have focused on the formation process and mechanical properties of crustacean exoskeletons to inform the development of novel hybrid materials. ${ }^{50}$ A significant feature of these exoskeletons is the interface between the chitin fibrils and $\mathrm{CaCO}_{3}$. Although chitin fiber and $\mathrm{CaCO}_{3}$ are immiscible, they are closely associated with each other in the exoskeleton. Recently, it was found that several functional peptides

a

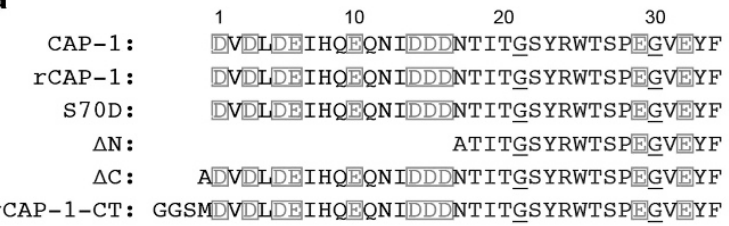

40

50

60

70

VKY I I DEDGYRVLESNAVPATADGVRADGAQGSFVSSEDDDDDD

VKY IADEDGYRVLESNAVPATADGVRADGAQGSFVSSEDDDDDD

VKY IADEDGYRVLESNAVPATADGVRADGAQGSFVDSEDDDDDD

VKYIADEDGYRVLESNAVPATADGVRADGAQGSFVSSEDDDDDD

VKY IADEDGYRVLESNAVPATADGVRADGAQ

VKYIADEDGYRVLESNAVPATADGVRADGAQGS (FVSSEDDDDDD)

S: phosphoserine $\mathrm{X}$ : acidic amino acid

$\underline{X}$ : Rebers-Riddiford consensus sequence
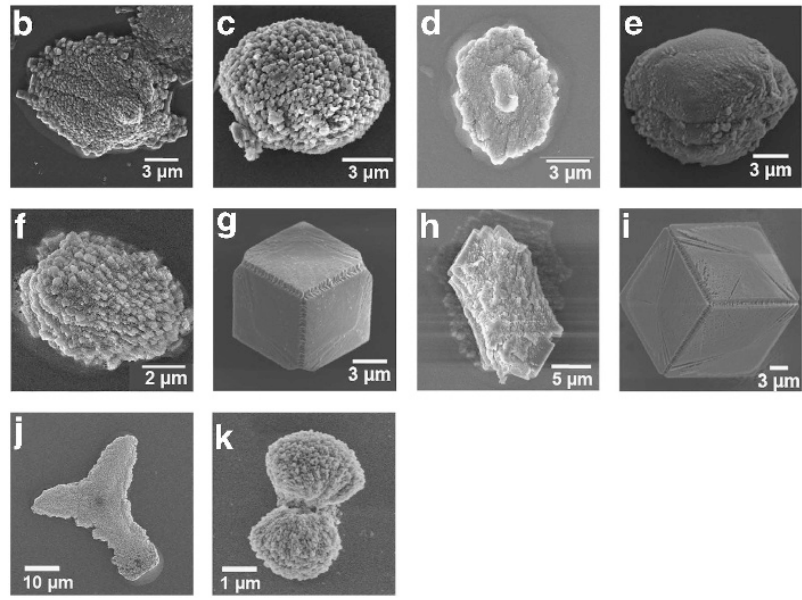

Figure 3 (a) Comparison of the sequences of CAP-1 and its related peptides. (b-k) Scanning electron microscopy (SEM) images of $\mathrm{CaCO}_{3}$ formed in the presence of various types of recombinant peptides. ( $b$ and $\mathbf{c}$ ) rCAP-1, (d and e) rCAP-1-S70D, ( $f$ and $\mathbf{g}$ ) $\Delta \mathrm{N}$, ( $\mathbf{h}$ and $\mathbf{i}$ ) $\Delta \mathrm{C}$ and ( $\mathbf{j}$ and $\mathbf{k}$ ) rCAP-1-CT. Each image on the left side is $\mathrm{CaCO}_{3}$ formed on a chitin matrix, and the right image is $\mathrm{CaCO}_{3}$ formed on a glass substrate. Reproduced with permission from the reference. A full color version of this figure is available at Polymer Journal online. act at the interface of these two components, resulting in the fusion of the chitin framework with $\mathrm{CaCO}_{3}$ at the molecular level (Figure 2e). In 2000, the mineralization-related acidic peptide called CAP-1 was isolated from the crayfish exoskeleton by Inoue et al. ${ }^{51}$ According to an assay of crystal growth inhibitory activity, CAP-1 is the most effective peptide for inducing $\mathrm{CaCO}_{3}$ crystallization within insoluble organic matrices in the cuticle. CAP-1 also has several functional domains similar to the Pif complex (Figure 2e). CAP-1 is composed of acidic peptides bearing an Asp-repeating fragment at the $\mathrm{C}$ terminus and a phosphoserine residue at position 70 that may interact with calcium ions and stabilize the amorphous precursors of $\mathrm{CaCO}_{3}$. CAP-1 has a chitin-binding sequence in the central region of the peptide. These functional domains collaborate to concentrate $\mathrm{Ca}^{2+}$ ions at the chitin surface and to stabilize the amorphous precursors, resulting in the deposition of the amorphous precursors of $\mathrm{CaCO}_{3}$ onto the chitin fibrils. CAP-1 was also examined in a $\mathrm{CaCO}_{3}$ crystallization experiment by using $\mathrm{CaCO}_{3}$ supersaturated solution ${ }^{21}$ to understand the structure-function relationships of the peptide. CAP-1 induces the formation of $\mathrm{CaCO}_{3}$ thin films on the chitin matrix with the $\mathrm{c}$ axis of the thin-film crystals unidirectionally aligned parallel to the surface (Figure 2f). ${ }^{31}$ It is noteworthy that no oriented crystals are observed when a glass substrate is used (Figure $2 \mathrm{~g}$ ). The crystallographic orientation of the thin-film crystal depends on the specific interaction between the chitin-binding site of CAP-1 and the chitin fibrils in the matrix.

These biomineral-related proteins, such as Pif and CAP-1, exist at the biomacromolecule and mineral interface to bind these two components during the formation of an organism's hard tissues. These studies on the structure-function relationships of biomineralizationrelated proteins might illuminate useful information for the bioinspired design of functional molecules that may be used for the development of new hybrid materials.

\section{MOLECULAR DESIGNS FOR THE FORMATION OF BIOMIMETIC HYBRID MATERIALS (I)}

Understanding the roles of the biomacromolecules involved in biomineralization is a shortcut to developing novel functional hybrid materials through biomimetic approaches. To clarify the effects of each functional component of the crayfish peptides on the formation of biominerals, relevant peptides have been designed and synthesized (Figure 3a). ${ }^{31-33,49}$ The types of $\mathrm{CaCO}_{3}$ obtained on chitin or glass substrates in the presence of the recombinant peptides as soluble additives are depicted in Figures $3 \mathrm{~b}-\mathrm{k}$. All of the peptides influence the crystallization of $\mathrm{CaCO}_{3}$ because they are acidic peptides. We observed a significant difference in the morphology and orientation of the crystals, which suggests that these parameters may be dependent on the chemical structures of the recombinant peptides.

To investigate the control over morphology, the phosphorous group at the 70th position was substituted with $\mathrm{OH}$ and carboxylic acid in the recombinant peptides. ${ }^{31}$ Significant changes were observed in the surface morphology of the $\mathrm{CaCO}_{3}$ formed on the glass substrates (Figure 3c). It was revealed that the functional group at position 70 greatly influences the crystallization of $\mathrm{CaCO}_{3}$. Notably, the surface morphology of the crystals changed gradually according to the strength of the acidic groups present on the 70th residues (Figures $2 \mathrm{f}, \mathrm{g}$ and $3 \mathrm{~b}-\mathrm{e}$ ). ${ }^{32} \Delta \mathrm{N}$ and $\Delta \mathrm{C}$ are recombinant peptides that lack the 17 residues at the $\mathrm{N}$ or $\mathrm{C}$ terminus. A comparison between the crystals obtained with $\Delta \mathrm{N}$ and $\Delta \mathrm{C}$ shows that the Asp repeat at the $\mathrm{C}$ terminus also has significant effects on the morphology of $\mathrm{CaCO}_{3}$ (Figures 3e-i). ${ }^{32}$ The deleted peptides were designed to possess the same number of acidic amino-acid residues. In the 
presence of $\Delta \mathrm{C}$, the lack of a $\mathrm{C}$ terminus induced the formation of grains of $\mathrm{CaCO}_{3}$ on the chitin matrix, due to a decrease in the interaction with calcium ions. However, the effects of $\Delta \mathrm{N}$ on $\mathrm{CaCO}_{3}$ crystallization were similar to those of CAP-1, even though $\Delta \mathrm{N}$ lacked 17 residues. These results indicate that the $\mathrm{C}$-terminal acidic region has a greater influence on $\mathrm{CaCO}_{3}$ crystallization than the $\mathrm{N}$-terminal acidic region. When the acidic region at the $\mathrm{C}$ terminus was elongated, triangular $\mathrm{CaCO}_{3}$ thin films were obtained on the chitin matrix (Figures $3 \mathrm{j}$ and $\mathrm{k}$ ). ${ }^{33}$ The expanded acidic portion strongly stabilizes the amorphous precursors through polymer effects. The stabilization of the precursors subsequently reduces the crystal growth rate. The selective adsorption of the peptides onto specific faces of the $\mathrm{CaCO}_{3}$ through stereochemical recognition might lead to the formation of these plate-like tripodal crystals.

However, the crystallographic orientation of the thin films also strongly depends on the specific interaction between the chitinbinding sequence and the chitin fibrils in the matrix. All of the recombinant peptides, which have the chitin-binding sequence, induce the formation of unidirectionally oriented $\mathrm{CaCO}_{3}$ thin films on the chitin matrix identical to those obtained in the presence of natural

a
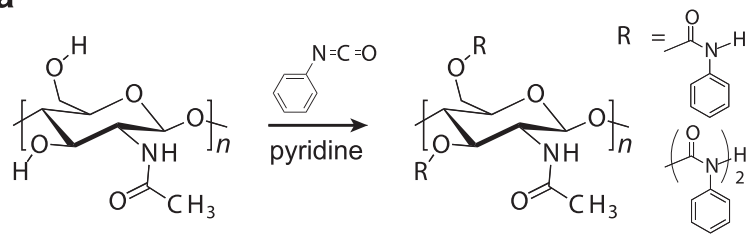

b
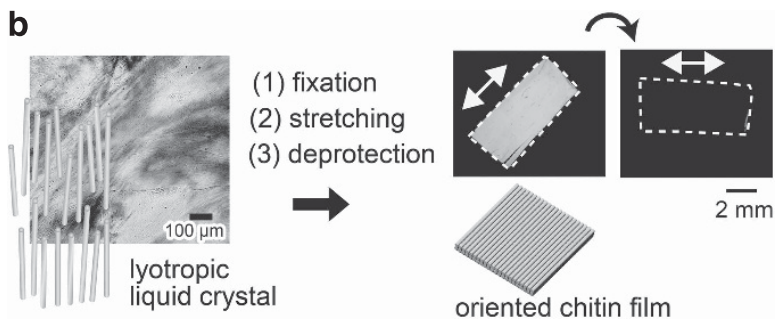

C
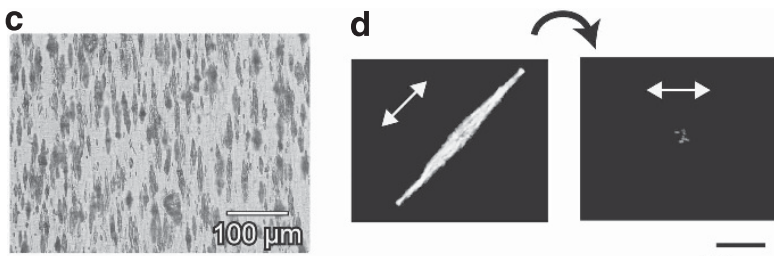

$15 \mu \mathrm{m}$

e

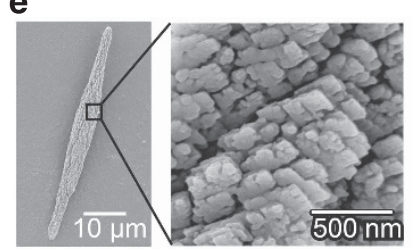

f

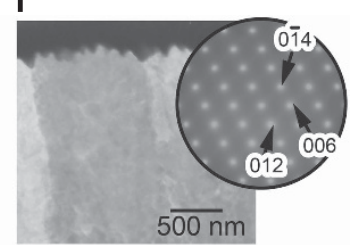

Figure 4 Schematic illustration of the process for preparing macroscopically ordered $\mathrm{CaCO}_{3} /$ organic hybrids using oriented chitin templates. (a) Synthetic scheme of chitin phenylcarbamate. (b) Illustration of the preparation of oriented chitin templates. (c) Photograph of the obtained hybrids, (d) polarizing optical microscopic images of isolated crystals, (e) scanning electron microscopy (SEM) images and (f) tunneling electron microscopy (TEM) image of an oriented crystal. Reproduced with permission from the reference.
CAP-1. The stabilization of the amorphous precursors in the chitin matrix before nucleation might be a key process in the formation of macroscopically oriented crystals. The effects of the chitin-binding site on crystallization were investigated using a chitosan matrix. ${ }^{33}$ Although chitosan is the deacetylated derivative of the chitin polymer, the binding strength of the recombinant peptides to chitosan is lower than that to chitin. When crystallization experiments were conducted by using a chitosan matrix in the presence of these recombinant peptides, round thin films were obtained instead of oriented thin films. The weak interactions between the peptides and the matrix suppressed the formation of oriented crystals. The lack of strong specific interactions changed these peptides from functional polymers to simple acidic polymers, such as PAA. Synthetic oligopeptides without the chitin-binding sequence also induce the formation of non-oriented small grains on a chitin matrix. ${ }^{31}$ These results provide us with information regarding the molecular design of functional molecules for the development of organic/inorganic hybrids. The structures of the individual functional domains of the peptides are an important design feature for the formation of hybrid materials.

\section{MOLECULAR DESIGNS FOR THE FORMATION OF BIOMIMETIC HYBRID MATERIALS (II)}

As mentioned earlier, the exoskeletons of crustaceans are good examples to explore to improve the design strategies of structural materials. The mechanical properties of the exoskeleton, such as ductility, toughness and a low weight, are directly related to its hierarchical structures. These elaborate structures and the mild conditions under which the structures form have been recognized as attractive strategies for the construction of biomimetic hybrid materials with hierarchical structures. It is worth studying the ordered structures of liquid crystalline materials as potential templates for inducing hierarchical structures in our target hybrid materials. Liquid crystals are a state of matter that combines the anisotropy of crystals and the fluidity of liquid. ${ }^{52,53}$ Liquid crystals can easily form large domains of orientation on a macroscopic scale. Capitalizing on this characteristic, unidirectionally oriented chitin templates have been prepared with liquid crystalline precursors. ${ }^{54}$ Although chitin is difficult to dissolve in any solvent because the chitin fibrils form aggregates through intermolecular hydrogen bonding, chitin phenylcarbamate, which has a protective group at the $\mathrm{OH}$ position, can be dissolved in polar solvents (Figure 4). ${ }^{55,56}$ Moreover, chitin phenylcarbamate exhibits lyotropic nematic liquid crystallinity in concentrated solutions (somewhat more than $15 \mathrm{wt} \%$ ) because of the rigidity and intermolecular interactions of this compound. These liquid crystals can be converted to the gel state when they are immersed in solvents in which they have poor solubility, such as methanol. After stretching and deprotection, a unidirectionally oriented chitin matrix was successfully obtained (Figure $4 \mathrm{~b}$ ). The oriented chitin film is composed of stretched chitin polymer chains that are oriented at a macroscopic scale. Calcium chloride aqueous solution containing PAA was used to carry out $\mathrm{CaCO}_{3}$ crystallization. The solution containing the matrices was placed in a closed desiccator together with ammonium carbonate. When the resultant gel matrices are used as template for the crystallization of $\mathrm{CaCO}_{3}$, unidirectionally aligned rod-shaped crystals $\sim 80 \mu \mathrm{m}$ in size are formed within the oriented chitin matrix (Figures $4 \mathrm{c}$ and d). Scanning electron microscopy and tunneling electron microscopy observations of the rodshaped crystals formed in the oriented chitin matrix (Figures $4 \mathrm{e}$ and $\mathrm{f}$ ) reveal that the crystals are assemblies of submicron-size rhombohedral calcite crystals with a single crystalline orientation, which are known as mesocrystals. ${ }^{57}$ 
Another way of developing hybrid materials via the use of liquid crystalline templates has also been reported. ${ }^{58}$ It is well known that polysaccharide nanowhiskers have lyotropic nematic and chiral nematic liquid crystallinity. ${ }^{59-61}$ Because of the similarity between the hierarchical helical structure of crustacean exoskeletons and that of cholesteric liquid crystals, the liquid crystalline suspensions of polysaccharides were used as templates for the development of threedimensional structural hybrid materials similar to the crustaceanderived biominerals. The lyotropic liquid crystalline chitin suspension was obtained by acid hydrolysis of $\alpha$-chitin, as reported by Revol and Marchessault. ${ }^{61}$ After ultrasonication, the resulting chitin whiskers were dispersed in water with a desired $\mathrm{pH}$ value because of their electronic repulsion. At the appropriate concentration and $\mathrm{pH}$, the whisker suspension displays a fingerprint texture, suggesting that the suspension forms a chiral nematic helical structure (cholesteric phase). The helical structure can be preserved in gel form and then serve as the template for $\mathrm{CaCO}_{3}$ crystallization (Figure 5). After the crystallization of $\mathrm{CaCO}_{3}$ in the presence of PAA, by using sublimation method, the $\mathrm{CaCO}_{3} /$ chitin hybrids are formed with a composition of $20 \mathrm{wt} \%$ adsorbed water molecules, $60 \mathrm{wt} \%$ organic polymer and a

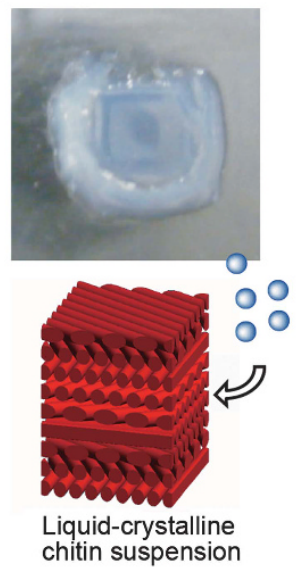

$\mathrm{CaCO}_{3}$ crystallization
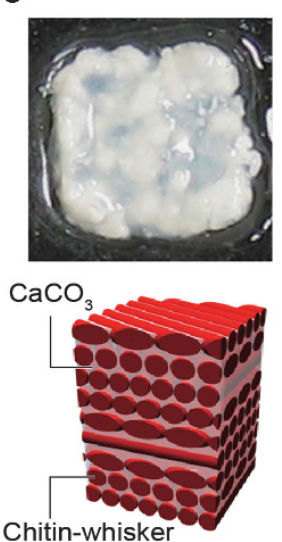
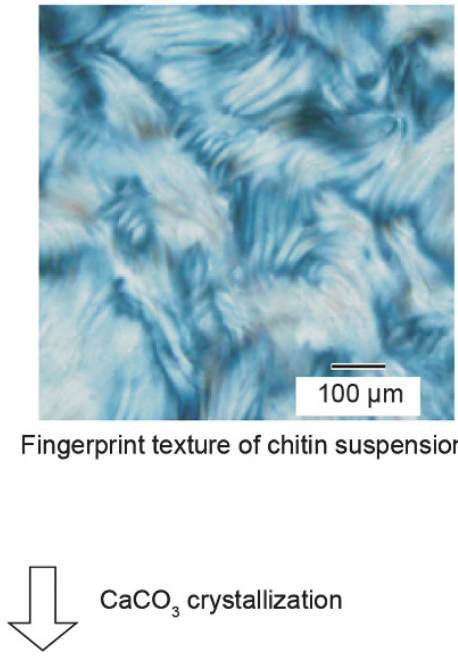

Fingerprint texture of chitin suspension

d

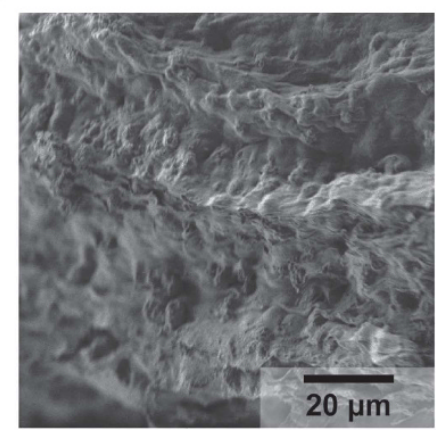

Cross-sectional view of

fractured surface of chitin $/ \mathrm{CaCO}_{3}$ hybrid
Figure 5 Schematic illustration of chitin/ $\mathrm{CaCO}_{3}$ hybrids formed using a chitin suspension. ( $\mathbf{a}$ and $\mathbf{b}$ ) Photographs of lyotropic liquid crystalline chitin suspensions. (c) Photograph and (d) scanning electron microscopy (SEM) image of an obtained $\mathrm{CaCO}_{3} /$ chitin hybrid. Reproduced with permission from the reference.

$20 \mathrm{wt} \%$ inorganic crystal, as determined by thermogravimetric analysis. ${ }^{58}$ The obtained hybrid materials have hierarchical ordered structures similar to that of the exoskeleton of crustaceans. These structures potentially enhance the mechanical as well as the optical properties of the resultant materials. ${ }^{62}$

The self-organized macroscopic orientation of liquid crystalline polymers is one of the advantages of using these polymers in the development of hybrid materials. Liquid crystal polymers that exhibit cholesteric, smectic and columnar phases could be applied as templates for new hybrid structures. This liquid crystalline methodology might be useful for the preparation of novel oriented hybrid materials based on a wide range of functional inorganic crystals.

A polymer brush matrix is one of the organic template candidates that may be used in the development of novel hybrid materials with dynamic and stimuli-responsive properties. A polymer brush is a thinfilm polymer that covalently attaches by one end of the polymer chain to the surface of a substrate. ${ }^{63}$ Such polymer layers possess excellent stability over long time periods in various solvents at a wide range of temperatures. Because of recent advances in surface-initiated, controlled living radical polymerization techniques, ${ }^{64}$ a more precise control of the thickness, composition, and density has been accomplished for polymer brushes compared with chemically grafted or physisorbed polymers. Moreover, polymer brushes are a particularly attractive approach in creating stimuli-responsive matrices. The formation of a responsive polymer involves the application of a water-soluble polymer coating that can be subsequently used as a platform for the nucleation of inorganic crystals. ${ }^{65}$ When thermoresponsive PNIPAm (poly( $N$-isopropylacrylamide)) is used as a polymer brush template, for example, the formation of vaterite thin films is induced in the presence of PAA. ${ }^{65-67}$ Furthermore, conformational changes in the PNIPAm brush matrix significantly influences the morphologies and preferential orientations of the resultant
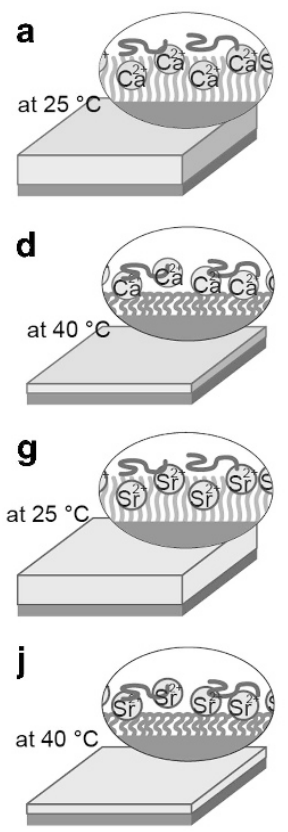

Figure 6 (a-f) Illustration of $\mathrm{CaCO}_{3}$ thin films formed on a thermoresponsive polymer template. (b) Polarizing micrograph and (c) Scanning electron microscopy (SEM) image of $\mathrm{CaCO}_{3}$ thin films developed at $25^{\circ} \mathrm{C}$ and (d-f) at $40^{\circ} \mathrm{C}$. (g-I) Illustration of $\mathrm{SrCO}_{3}$ thin films formed on a thermoresponsive polymer template. (g-i) at $25^{\circ} \mathrm{C}$ and $(\mathbf{j}-\mathbf{I})$ at $40^{\circ} \mathrm{C}$. Reproduced with permission from the reference.
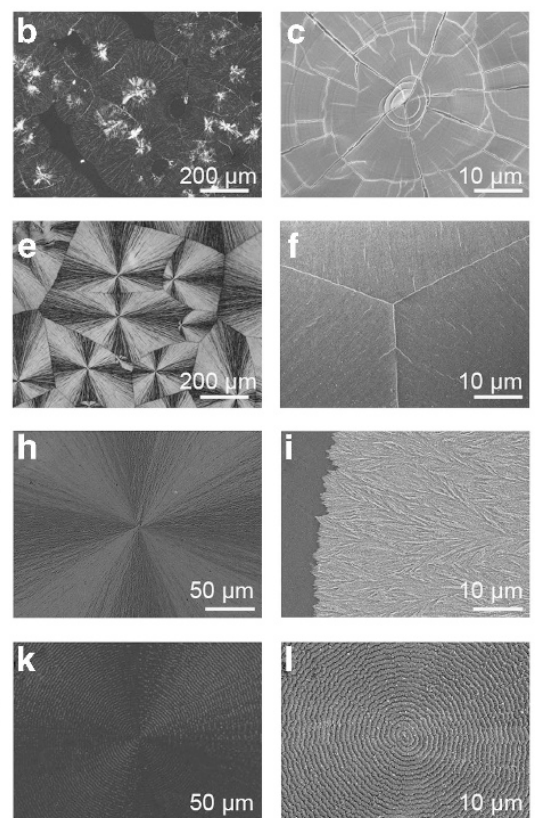

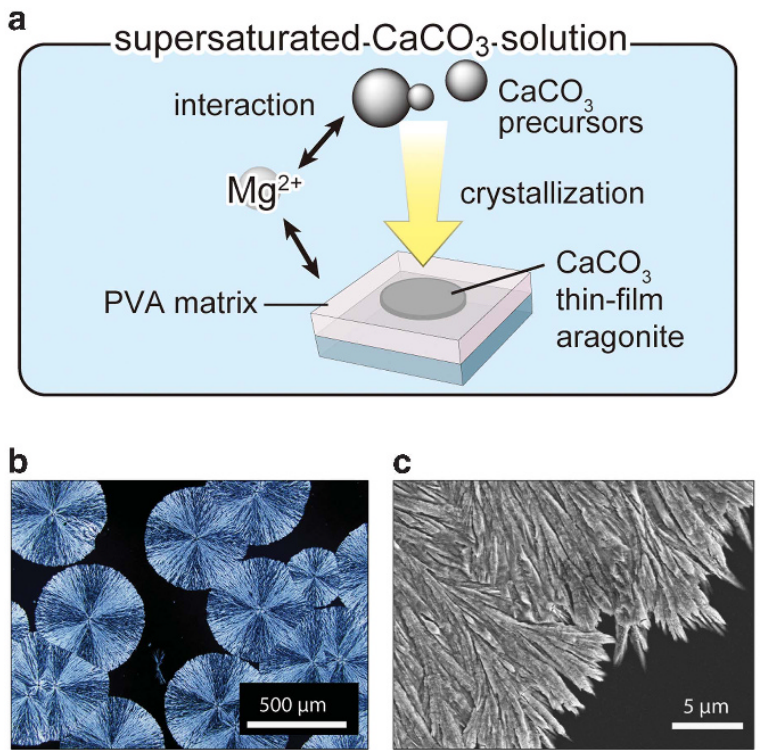

d

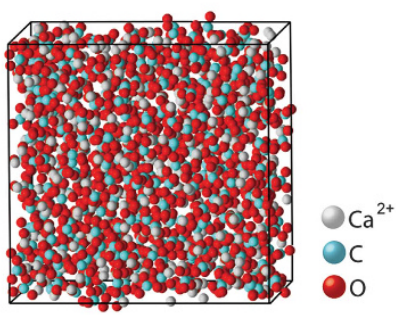

e

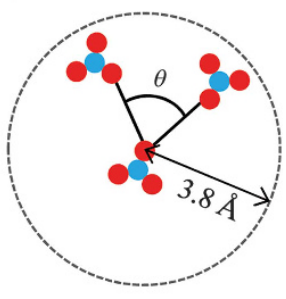

f

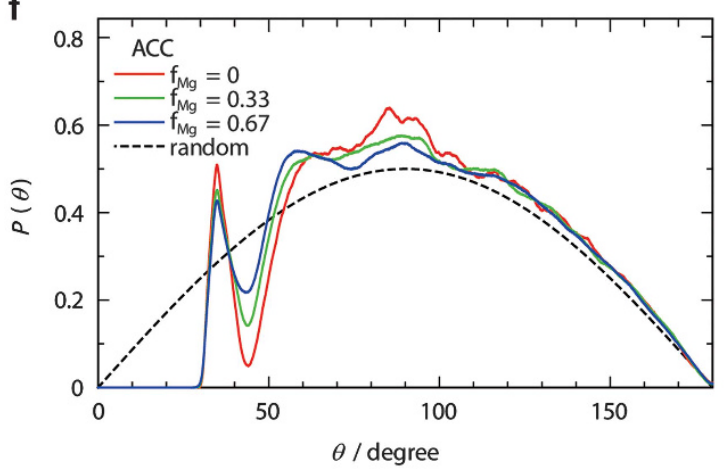

Figure 7 (a) Formation of thin-film $\mathrm{CaCO}_{3}$ in the presence of $\mathrm{Mg}^{2+}$ ion. (b) Polarizing optical micrograph and (c) scanning electron microscopy (SEM) image of the $\mathrm{CaCO}_{3}$ thin films grown on PVA matrices in the presence of $\mathrm{Mg}^{2+}(5 \mathrm{~mm})$. (d) Illustration of the $\mathrm{CaCO}_{3}$ simulation system. (e) The definition of $\theta$ formed by the three nearest-neighbor $\mathrm{O}$ atoms of the $\mathrm{CO}_{3}{ }^{2-}$ ions. (f) $P(\theta)$ for $\mathrm{ACC}$ at each $f_{\mathrm{Mg}} . P(\theta)=1 / 2 \sin \theta$ are also shown for the random distribution. Reproduced with permission from the reference.

vaterite/PNIPAm hybrid thin films (Figures $6 \mathrm{a}-\mathrm{f}$ ). $\mathrm{CaCO}_{3}$ thin films with the $\mathrm{c}$ axis preferentially perpendicular to the brush template are obtained below the lower critical solution temperature, whereas crystallization above the lower critical solution temperature induces the formation of vaterite thin films with the $\mathrm{c}$ axis parallel to the brush template. In addition, the surface morphology of $\mathrm{SrCO}_{3}{ }^{68}$ thin films have also been tuned with a PNIPAm brush template (Figures $6 \mathrm{~g}-1){ }^{67}$

The use of polymer brushes also contributes to the design of organic/inorganic functional hybrid-coating materials. These studies
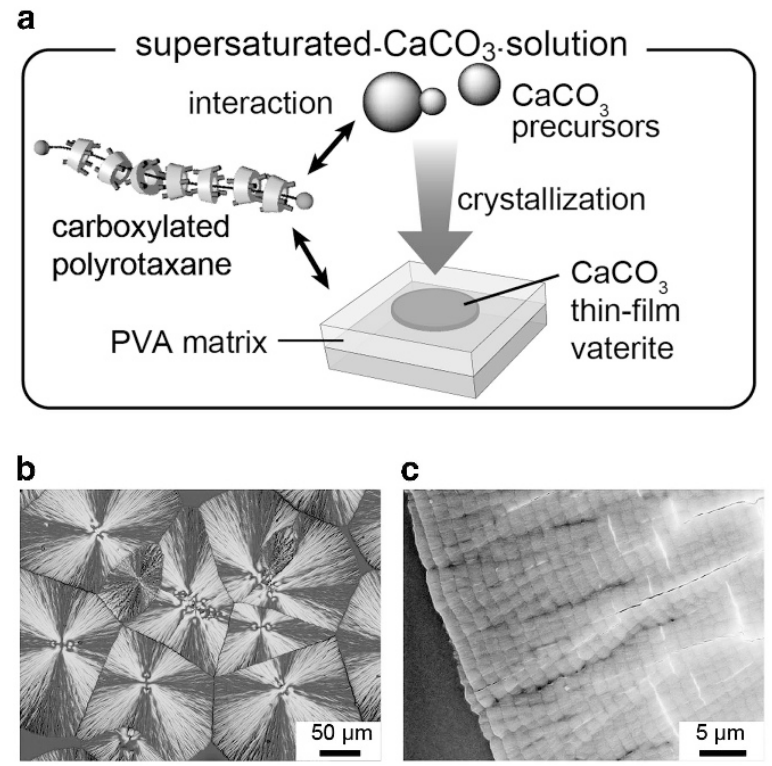

Figure 8 (a) Formation of thin-film $\mathrm{CaCO}_{3}$ via ACC precursors stabilized by supramolecules. (b) Polarizing optical microscopic image and (c) scanning electron microscopy (SEM) image of the obtained thin-film crystals formed on the PVA matrix in the presence of carboxylated polyrotaxane. Reproduced with permission from the reference.

demonstrate that polymer brush matrices are effective crystallization matrices for inorganic minerals. The use of a stimuli-responsive polymer brush matrix template is a promising method for realizing control over the morphology and orientation of hybrid materials.

\section{CRYSTALLIZATION FROM ACC STATES AND THE FORMATION MECHANISM INVOLVED}

It has been well recognized for a decade that ACC, the precursor form of crystalline $\mathrm{CaCO}_{3}$, has an important role in the formation mechanisms of biominerals, sea urchin spicules, ${ }^{69}$ crustacean exoskeletons $^{70,71}$ and the nacre of seashells. ${ }^{72}$ Recently, material scientists have also demonstrated that the biomimetic synthesis of crystalline $\mathrm{CaCO}_{3}$ particles and thin films via stabilized ACC precursors is possible. ${ }^{28,62,73}$ For example, Sommerdijk and coworkers ${ }^{74}$ directly observed ACC particles before they crystallized on a Langmuir-Blodgett film template. In this section, the ACC precursor is described with a focus on its use in the development of hybrid materials. The formation mechanisms of the hybrid materials obtained with ACC precursors are also covered.

ACC is thermodynamically unstable and crystallizes rapidly in the presence of water. It is well known that acidic polymers containing carboxylic acids and phosphoric acids can stabilize ACC and suppress its crystallization. Recently, it was found that not only acidic polymers but also small molecules such as $\mathrm{Mg}^{2+}$ act as stabilizers for ACC. ${ }^{75}$ Because $\mathrm{Mg}^{2+}$ is abundant in seawater ${ }^{76}$ and is incorporated into the biominerals of marine organisms, ${ }^{77}$ intensive research has already been reported concerning the role of $\mathrm{Mg}^{2+}$ in the biomineralization of $\mathrm{CaCO}_{3}$. For example, in crustacean exoskeletons, the amorphous region was found to contain more $\mathrm{Mg}^{2+}$ than the crystalline region, ${ }^{78}$ and the distribution of $\mathrm{Mg}^{2+}$ in the teeth of sea urchins is also regulated. Inspired by the role of $\mathrm{Mg}^{2+}$ in biomineralization, $\mathrm{Mg}^{2+}$ has been used as an additive in synthetic systems to control $\mathrm{CaCO}_{3}$ crystallization by decreasing the crystallization rate, stabilizing the 
amorphous precursors and providing control over both morphology and polymorph formation. ${ }^{79}$

The role of $\mathrm{Mg}^{2+}$ in the crystallization of $\mathrm{CaCO}_{3}$ on organic templates was recently investigated to obtain useful information for the development of functional thin-film hybrid materials through sublimation method by using calcium chloride solution together with ammonium carbonate (Figure 7). ${ }^{29}$ In the presence of $\mathrm{Mg}^{2+}$, ACC precursors were stabilized in supersaturated $\mathrm{CaCO}_{3}$ solutions, and thin films of $\mathrm{CaCO}_{3}$ were formed on the annealed poly(vinyl alcohol) (PVA) matrices. The polymorph of the thin films was aragonite, as confirmed by infrared spectroscopy and X-ray diffraction measurements. It is of interest that the ionic additive alone (without additional polymer additives) resulted in thin films of $\mathrm{CaCO}_{3}$ on the PVA matrices. Both the growth rate and surface morphology of the aragonite thin films were dependent on the concentration of $\mathrm{Mg}^{2+}$ in the crystallization solution; in the absence of PVA matrices, no thin films were formed despite the presence of $\mathrm{Mg}^{2+}$. To evaluate the effects of $\mathrm{Mg}^{2+}$ on the stabilization of ACC, a molecular dynamics simulation was conducted (Figure 7d). ${ }^{29,80}$ When the $\mathrm{Mg}^{2+}$ content of the ACC solution increases, the peaks in the distribution functions, which indicate the local structure of the ACC (Figure 7e), become broad, and the complete distribution function approaches a random distribution function (Figure 7f). These results from the molecular dynamics simulation of the $\mathrm{CaCO}_{3}$ precursor suggest that the transition of ACC to a crystalline form is suppressed in the presence of $\mathrm{Mg}^{2+}$. The possible mechanism of the formation of thin-film hybrid materials by $\mathrm{Mg}^{2+}$ can be explained as follows: In the crystallization solution, $\mathrm{Mg}$ ions stabilize the ACC precursor and suppress $\mathrm{CaCO}_{3}$ crystal nucleation. In contrast, the PVA matrix may promote $\mathrm{CaCO}_{3}$ crystallization by assisting aragonite nucleation via the interaction of the functional groups of the two species. When the amorphous precursor is attached to the surface of the PVA matrix, nucleation and crystal growth occur, and as a result, hybrid thin films are formed. ${ }^{29}$

Supramacromolecules ${ }^{81-83}$ are also useful for developing hybrid materials. $^{30}$ To this end, acidic supramacromolecules have been designed and synthesized as additives for the stabilization of ACC precursors. Polyrotaxane structures composed of acidic cyclodextrin and polyethylene oxide were synthesized (Figure 8). ${ }^{84,85}$ In the presence of carboxylated polyrotaxane, vaterite thin films were formed on PVA matrices (Figure 8$).{ }^{30}$ The results suggest that the monomeric cyclodextrin units entrapped by polyrotaxane have a polymer-like effect on $\mathrm{CaCO}_{3}$ crystallization, despite the highly mobile characteristics of these cyclodextrin units in supramolecular structures. The ACC precursors, stabilized by the acidic supramacromolecules, are essential for the formation of thin-film hybrid materials. Thin films are not obtained when the individual carboxylated $\alpha$-cyclodextrin units are used as additives because of the lack of ACC stabilization. Previously, covalent polymers were used to develop the thin-film growth of $\mathrm{CaCO}_{3}$. The use of supramacromolecules extends our understanding of the formation mechanisms of thin-film $\mathrm{CaCO}_{3}$ based hybrid materials. ${ }^{86}$

\section{CONCLUSIONS}

In this review, the roles of organic (macro)molecules as templates or additives have been discussed in the context of preparing new hybrid materials. Because of technological advancements in organic, polymer and materials sciences, we are able to control the structures and functions of organic materials. As a result, a variety of complex hybrid material structures have been achieved using designed macromolecular templates. However, the construction of hybrid materials using biomimetic methods inspired by natural materials still remains a challenge. We should attempt to synthesize new materials that can overcome the limitations of biological materials and exhibit versatile characteristics such as semiconductivity ${ }^{87}$ and special optical ${ }^{88}$ and magnetic properties. ${ }^{89}$ This might be accomplished through a collaboration among a wide variety of scientific fields, including organic chemistry, polymer chemistry, inorganic chemistry, physics, biology and engineering. Further understanding the process of biomineralization and the roles of biomineralization-relevant proteins will enable us to design macromolecular templates for functional inorganic materials, resulting in new functional hybrid materials.

\section{ACKNOWLEDGEMENTS}

I thank all the coworkers for their contributions and specially thank Professor Takashi Kato (The University of Tokyo, Toyko, Japan) and Professor Eiji Yashima (Nagoya University, Nagoya, Japan) for their encouragement. I would also like to thank the Nanotechnology Platform of The University of Tokyo for the tunneling electron microscopy observation. A part of this work was supported by a Grant-in-Aid for Scientific Research (no. 22107003) on the Innovative Areas, 'Fusion Materials: Creative Development of Materials and Exploration of Their Function through Molecular Control' (area no. 2206) from the Ministry of Education, Culture, Sports, Science and Technology (MEXT) and the SEKISUI Chemical Grant Program for research on manufacturing based on innovations inspired by nature from the SEKISUI Foundation, Tokyo, Japan.

1 Mann, S. in Biomineralization Principles and concepts in Bioinorganic Materials Chemistry (eds Compton R. G., Davies S. G., Evans J.)(Oxford University Press, Oxford, UK, 2001).

2 Bäuerlein E. Biomineralization, (Wiley-VCH, Weinheim, Germany, 2000).

3 Bäuerlein E., Behrens P., Epple M. Handbook of Biomineralization, (Wiley-VCH, Weinheim, Germany, 2007).

4 Addadi, L. \& Weiner, S. Control and design principles in biological mineralization. Angew. Chem. Int. Ed. Engl. 31, 153-169 (1992).

5 Okumura, K. \& de Gennes, P.-G. Why is nacre strong? Elastic theory and fracture mechanics for biocomposites with stratified structures. Eur. Phys. J. E 4, 121-127 (2001)

6 Jackson, A. P., Vincent, J. F. V. \& Turner, R. M.. The mechanical design of nacre. Proc. R. Soc. Lond. Ser. B 234, 415-440 (1988).

7 Aizenberg, J., Tkachenko, A., Weiner, S., Addadi, L. \& Hendler, G. Calcitic microlenses as part of the photoreceptor system in brittlestars. Nature 412, 819-822 (2001).

8 Aizenberg, J., Sundar, V. C., Yablon, A. D., Weave, J. C. \& Chen, G. Biological glass fibers: correlation between optical and structural properties. Proc. NatI. Acad. Sci. USA 101, 3358-3363 (2004)

9 Arakaki, A., Nakazawa, H., Nemoto, M., Mori, T. \& Matsunaga, T. Formation of magnetite by bacteria and its application. J. R. Soc. Interface 5, 977-999 (2008).

10 Addadi, L. \& Weiner, S. A pavement of pearl. Nature 389, 912-915 (1997).

11 Calvert, P. \& Mann, S. Synthetic and biological composites formed by in situ precipitation. J. Mater. Sci. 23, 3801-3815 (1988).

12 Heuer, A. H., Fink, D. J., Laraia, V. J., Arias, J. L., Calvert, P. D., Kendall, K., Messing, G. L., Blackwell, J., Rieke, P. C., Thompson, D. H., Wheeler, A. P., Veis, A. \& Caplan, A. I. Innovative materials processing strategies: a biomimetic approach. Science 255, 1098-1105 (1992).

13 Kato, T. Polymer/calcium carbonate layered thin-film composites. Adv. Mater. 12, 1543-1546 (2000).

14 Kato, T., Sugawara, A. \& Hosoda, N. Calcium carbonate-organic hybrid materials. Adv. Mater. 14, 869-877 (2002).

15 Kato, T., Sakamoto, T. \& Nishimura, T. Macromolecular templating for the formation of inorganic-organic hybrid structures. MRS Bull. 35, 127-132 (2010).

16 Meldrum, F. C. Calcium carbonate in biomineralisation and biomimetic chemistry. Int. Mater. Rev. 48, 187-224 (2003).

17 Meldrum, F. C. \& Cölfen, H. Controlling mineral morphologies and structures in biological and synthetic systems. Chem. Rev. 108, 4332-4342 (2008).

18 Sommerdijk, N. A. J. \& de With, G. Biomimetic $\mathrm{CaCO}_{3}$ mineralization using designer molecules and interfaces. Chem. Rev. 108, 4499-4550 (2008).

19 Sugawara-Narutaki, A. Bio-inspired synthesis of polymer-inorganic nanocomposite materials in mild aqueous systems. Polym. J. 45, 269-276 (2013).

20 Kato, T., Suzuki, T. \& Irie, T. Layered thin-film composite consisting of polymers and calcium carbonate: a novel organic/inorganic material with an organized structure. Chem. Lett. 29, 186-187 (2000).

21 Kato, T., Suzuki, T., Amamiya, T., Irie, T., Komiyama, M. \& Yui, H. Effects of macromolecules on the crystallization of $\mathrm{CaCO}_{3}$ the formation of organic/inorganic composites. Supramol. Sci. 5, 411-415 (1998). 
22 Hosoda, N. \& Kato, T.. Thin-film formation of calcium carbonate crystals: effects of functional groups of matrix polymers. Chem. Mater. 13, 688-693 (2001)

23 Hosoda, N., Sugawara, A. \& Kato, T. Template effect of crystalline poly(vinyl alcohol) for selective formation of aragonite and vaterite $\mathrm{CaCO}_{3}$ thin films. Macromolecules 36, 6449-6452 (2003)

24 Sugawara, A., Ishii, T. \& Kato, T. Self-organized calcium carbonate with regular surfacerelief structures. Angew. Chem. Int. Ed. 42, 5299-5303 (2003).

25 Sakamoto, T., Oichi, A., Nishimura, T., Sugawara, A. \& Kato, T. Calcium carbonate/ polymer thin-film hybrids: induction of the formation of patterned aragonite crystals by thermal treatment of a polymer matrix. Polym. J. 41, 522-523 (2009).

26 Sakamoto, T., Oichi, A., Oaki, Y., Nishimura, T., Sugawara, A. \& Kato, T. Three-dimensinal relief structures of $\mathrm{CaCO}_{3}$ crystal assemblies formed by spontaneous two-step crystal growth on a polymer thin film. Cryst. Growth Des. 9, 622-625 (2009).

27 Sakamoto, T., Nishimura, Y., Nishimura, T. \& Kato, T. Photoimaging of self-organized $\mathrm{CaCO}_{3} /$ polymer hybrid films by formation of regular relief and flat surface morphologies. Angew. Chem. Int. Ed. 50, 5856-5859 (2011).

28 Kajiyama, S., Nishimura, T., Sakamoto, T. \& Kato, T. Aragonite nanorods in calcium carbonate/polymer hybrids formed through self-organization processes from amorphous calcium carbonate solution. Small 10, 1634-1641 (2014).

29 Zhu, F., Nishimura, T., Sakamoto, T., Tomono, H., Nada, H., Okumura, Y., Kikuchi, H. \& Kato, $\mathrm{T}$. Tuning the stability of $\mathrm{CaCO}_{3}$ crystals with magnesium ions for formation of aragonite thin films on organic polymer templates. Chem. Asian J. 8, 3002-3009 (2013)

30 Zhu, F., Nishimura, T., Eimura, H. \& Kato, T. Supramolecular effects on formation of $\mathrm{CaCO}_{3}$ thin films on a polymer matrix. Cryst. Eng. Commun. 16, 1496-1501 (2014).

31 Sugawara, A., Nishimura, T., Yamamoto, Y., Inoue, H., Nagasawa, H. \& Kato, T. Selforganization of oriented calcium carbonate/polymer composites: effects of a matrix peptide isolated from the exoskeleton of a crayfish. Angew. Chem. Int. Ed. 45, 2876-2879 (2006)

32 Yamamoto, Y., Nishimura, T., Sugawara, A., Inoue, H., Nagasawa, H. \& Kato, T. Effects of peptides on $\mathrm{CaCO}_{3}$ crystallization: mineralization properties of an acidic peptide isolated from exoskeleton of a crayfish and its derivatives. Cryst. Growth Des. 8 , 4062-4065 (2008).

33 Kumagai, H., Matsunaga, R., Nishimura, T., Yamamoto, Y., Oaki, Y., Inoue, H., Nagasawa, $\mathrm{H}$., Tsumoto, K. \& Kato, $\mathrm{T} . \mathrm{CaCO}_{3} /$ chitin hybrids: effects of recombinant acidic peptides designed based on a peptide extracted from an exoskeleton of a crayfish on morphologies of the hybrids. Faraday Discuss. 159, 483-494 (2012).

34 Nishimura, T., Imai, H., Oaki, Y., Sakamoto, T. \& Kato, T. Preparation of thin-film hydroxyapatite/polymer hybrids. Chem. Lett. 40, 458-460 (2011).

35 Belcher, A. M., Wu, X. H., Christensen, R. J., Hansma, P. K., Stucky, G. D. \& Morse, D. E. Control of crystal phase switching and orientation by soluble mollusc-shell proteins. Nature 381, 56-58 (1996).

36 Watabe, N. \& Wilbur, K. M. Influence of the organic matrix on crystal type in molluscs. Nature 188, 334 (1960)

37 Miyamoto, H., Miyashita, T., Okushima, M., Nakano, S., Morita, T. \& Matsushiro, A. A carbonic anhydrase from the nacreous layer in oyster pearls. Proc. Natl. Acad. Sci. USA 93, 9657-9660 (1996).

38 Kono, M., Hayashi, N. \& Samata, T. Molecular mechanism of the nacreous layer formation in Pinctada maxima. Biochem. Biophys. Res. Commun. 269, 213-218 (2000)

39 Samata, T., Hayashi, N., Kono, M., Hasegawa, K., Horita, C. \& Akera, S. A new matrix protein family related to the nacreous layer formation of Pinctada fucata. FEBS Lett. 462, 225-229 (1999).

40 Sudo, S., Fujikawa, T., Nagakura, T., Ohkubo, T., Sakaguchi, K., Tanaka, M., Nakashima, K. \& Takahashi, T. Structures of mollusk shell framework proteins. Nature 387, 563-564 (1997)

41 Zhanga, Y., Xiea, L., Menga, Q., Jianga, T., Pub, R., Chena, L. \& Zhang, R. A novel matrix protein participating in the nacre framework formation of pearl oyster, Pinctada fucata. Comp. Biochem. Physiol. B 135, 565-573 (2003).

42 Miyashita, T., Takagi, R., Okushima, M., Nakano, S., Miyamoto, H., Nishikawa, E. \& Matsushiro, A. Complementary DNA cloning and characterization of pearlin, a new class of matrix protein in the nacreous layer of oyster pearls. Mar. Biotechnol. 2, 409-418 (2000)

43 Suzuki, M., Murayama, E., Inoue, H., Ozaki, N., Tohse, H., Kogure, T. \& Nagasawa, H. Characterization of Prismalin-14, a novel matrix protein from the prismatic layer of the Japanese pearl oyster (Pinctada fucata). Biochem. J. 382, 205-213 (2004).

44 Mann, K., Weiss, I. M., Andre, S., Gabius, H. -J. \& Fritz, M. The amino acid sequence of the abalone (Haliotis laevigata) nacre protein perlucin. Detection of a functional C-type lectin domain with galactose/mannose specificity. Eur. J. Biochem. 267 5257-5264 (2000)

45 Shen, X., Belcher, A. M., Hansma, P. K., Stucky, G. D. \& Morse, D. E. Molecular cloning and characterization of Lustrin $\mathrm{A}$, a matrix protein from shell and pearl nacre of haliotis rufescens. J. Biol. Chem. 272, 32472-32481 (1997).

46 Suzuki, M., Saruwatari, K., Kogure, T., Yamamoto, Y., Nishimura, T., Kato, T. \& Nagasawa, H. An acidic matrix protein, Pif, is a key macromolecule for nacre formation. Science 325, 1388-1390 (2009).

47 Fabritius, H.-O., Sachs, C., Triguero, P. R. \& Raabe, D. Influence of structural principles on the mechanics of a biological fiber-based composite material with hierarchical organization: the exoskeleton of the lobster homarus americanus. Adv. Mater. 21, 391-400 (2009)

48 Travis, D. F. Structural features of mineralization from tissue to macromolecula levels of organization in the decapod crustacea. Ann. $N$ Y Acad. Sci. 109 $177-245$ (1963).
49 Inoue, H., Ohira, T. \& Nagasawa, H. Significance of the $\mathrm{N}$ - and C-terminal regions of CAP-1, a cuticle calcification-associated peptide from the exoskeleton of the crayfish, for calcification. Peptides 28, 566-573 (2007).

50 Meyers, M. A., McKittrick, J. \& Chen, P.-Y. Structural biological materials: critical mechanics-materials connections. Science 339, 773-779 (2013).

51 Inoue, H., Ozaki, N. \& Nagasawa, H. Purification and structural determination of a phosphorylated peptide with anti-calcification and chitin-binding activities in the exoskeleton of the crayfish Procambarus clarkii. Biosci. Biotechnol. Biochem. 65, 1840-1848 (2001).

52 Goodby J. W., Collings P. J., Kato T., Tschierske C., Gleeson H., Raynes P. Handbook of Liquid Crystals: 8 Volume Set, 2nd edn (Wiley-VCH, Weinheim, Germany, 2014).

53 Kato, T., Mizoshita, N. \& Kishimoto, K. Functional liquid-crystalline assemblies: Selforganized soft materials. Angew. Chem. Int. Ed. 45, 38-68 (2006).

54 Nishimura, T., Ito, T., Yamamoto, Y., Yoshio, M. \& Kato, T. Macroscopically ordered polymer $/ \mathrm{CaCO}_{3}$ hybrids prepared by using a liquid-crystalline template. Angew. Chem. Int. Ed. 47, 2800-2803 (2008).

55 Yamamoto, C., Hayashi, T. \& Okamoto, Y. High-performance liquid chromatographic enantioseparation using chitin carbamate derivatives as chiral stationary phases. J. Chromatogr. A 1021, 83-91 (2003).

56 Kuse, Y., Asahina, D. \& Nishio, Y. Molecular structure and liquid-crystalline characteristics of chitosan phenylcarbamate. Biomacromolecules 10, 166-173 (2009).

57 Cölfen, H. \& Antonietti, M. Mesocrystals: inorganic superstructures made by highly. parallel crystallization and controlled alignment. Angew. Chem. Int. Ed. 44, 5576-5591 (2005)

58 Yamamoto, Y., Nishimura, T., Saito, T. \& Kato, T. $\mathrm{CaCO}_{3} /$ chitin-whisker hybrids: formation of $\mathrm{CaCO}_{3}$ crystals in chitin-based liquid-crystalline suspension. Polym. J. 42, 583-586 (2010)

59 Marchessault, R. H., Morehead, F. F. \& Walter, N. M. Liquid crystal systems from fibrillar polysaccharides. Nature 184, 632-633 (1959).

60 Revol, J.-F., Bradford, H., Giasson, J., Marchessault, R. H. \& Gray, D. G. Helicoidal selfordering of cellulose microfibrils in aqueous suspension. Int. J. Biol. Macromol. 14, 170-172 (1992)

61 Revol, J.-F. \& Marchessault, R. H. In vitro chiral nematic ordering of chitin crystallites. Int. J. Biol. Macromol. 15, 329-335 (1993).

62 Saito, T., Oaki, Y., Nishimura, T., Isogai, A. \& Kato, T. Bioinspired stiff and flexible composites of nanocellulose-reinforced amorphous $\mathrm{CaCO}_{3}$. Mater. Horiz 1 321-325 (2014).

63 Advincula, R. C Polymer Brushes: Synthesis, Characterization, Applications (Wiley-VCH, Weinheim, 2004)

64 Matyjaszewski, K. \& Xia, J. H. Atom transfer radical polymerization. Chem. Rev. 101 2921-2990 (2001).

65 Kumar, S., Ito, T., Yanagihara, Y., Oaki, Y., Nishimura, T. \& Kato, T. Crystallization of unidirectionally oriented fibrous calcium carbonate on thermoresponsive polymer brush matrices. Cryst. Eng. Commun. 12, 2021-2024 (2010)

66 Han, Y., Nishimura, T. \& Kato, T. Morphology tuning in the formation of vaterite crystal thin films with thermoresponsive poly( $\mathrm{N}$-isopropylacrylamide) brush matrices. Cryst. Eng. Commun. 16, 3540-3547 (2014)

67 Han, Y., Nishimura, T. \& Kato, T. Biomineralization-inspired approach to the development of hybrid materials: preparation of patterned polymer/strontium carbonate thin films using thermo-responsive polymer brush matrices. Polym. J. 46 499-504 (2014).

68 Tagaya, A. \& Koike, Y. Compensation and control of the birefringence of polymers for photonics. Polym. J. 44, 306-314 (2012).

69 Ma, Y. -R., Aichmayer, B., Paris, O., Fratzl, P., Meibom, A., Metzler, R.A., Politi, Y., Addadi, L., Gilbert, P. U. P. A. \& Weiner, S. The grinding tip of the sea urchin tooth exhibits exquisite control over calcite crystal orientation and Mg distribution. Proc. Natl. Acad. Sci. USA 106, 6048-6053 (2009).

70 Grunenfelder, L. K., Herrera, S. \& Kisailus, D. Crustacean-derived biomimetic components and nanostructured composites. Small 10, 3207-3232 (2014).

71 Raabe, D., Sachs, C. \& Romano, P. The crustacean exoskeleton as an example of a structurally and mechanically graded biological nanocomposite material. Acta Mater. 53, 4281-4292 (2005)

72 Addadi, L., Joester, D., Nudelman, F. \& Weiner, S. Mollusk shell formation: a source of new concepts for understanding biomineralization processes. Chem. Eur. J. 12, 981-987 (2006).

73 Oaki, Y., Kajiyama, S., Nishimura, T., Imai, H. \& Kato, T. Nanosegregated amorphous composites of calcium carbonate and an organic polymer. Adv. Mater. 20, 3633-3637 (2008)

74 Pouget, E. M., Bomans, P. H. H., Goos, J. A. C. M., Frederik, P. M., de With, G. \& Sommerdijk, N. A. J. M. The initial stages of template-controlled $\mathrm{CaCO}_{3}$ formation revealed by cryo-TEM. Science 323, 1455-1458 (2009).

75 Aizenberg, J., Lambert, G., Weiner, S. \& Addadi, L. Factors involved in the formation of amorphous and crystalline calcium carbonate: a study of an ascidian skeleton. J. Am. Chem. Soc. 124, 32-39 (2002).

76 Lippmann, F Sedimentary Carbonate Minerals, (Springer-Verlag, Berlin, Germany, 1973).

77 Raz, S., Hamilton, P. C., Wilt, F. H., Weiner, S. \& Addadi, L. The transient phase of amorphous calcium carbonate in sea urchin larval spicules: the involvement of proteins and magnesium ions in its formation and stabilization. Adv. Funct. Mater. 13, 480-486 (2003).

78 Tao, J.-H., Zhou, D.-M., Zhang, Z.-S., Xu, X.-R. \& Tang, R.-K. Magnesium-aspartatebased crystallization switch inspired from shell molt of crustacean. Proc. Natl. Acad. Sci. USA 106, 22096-22101 (2009). 
79 Davis, K. J., Dove, P. M. \& De Yoreo, J. J. The role of $\mathrm{Mg}^{2+}$ as an impurity in calcite growth. Science 290, 1134-1137 (2000).

80 Tomono, H., Nada, H., Zhu, F., Sakamoto, T., Nishimura, T. \& Kato, T. Effects of magnesium ions and water molecules on the structure of amorphous calcium carbonate: a molecular dynamics study. J. Phys. Chem. B 117, 14849-14856 (2013).

81 Ito, K. Novel entropic elasticity of polymeric materials: Why is slide-ring gel so soft? Polym. J. 44, 38-41 (2012).

82 Koyama, Y., Suzuki, Y., Asakawa, T., Kihara, N., Nakazono, K. \& Takata, T. Polymer architectures assisted by dynamic covalent bonds: synthesis and properties of boronate functionalized polyrotaxane and graft polyrotaxane. Polym. J. 44, 30-37 (2012).

83 Tanaka, Y. \& Naka, K. Synthesis of calcium carbonate particles with carboxylicterminated hyperbranched poly(amidoamine) and their surface modification. Polym. J. 44, 586-593 (2012).

84 Harada, A., Li, J. \& Kamachi, M. The molecular necklace: a rotaxane containing many threaded $\alpha$-cyclodextrins. Nature 356, 325-327 (1992).
85 Ooya, T., Eguchi, M., Ozaki, A. \& Yui, N. Carboxyethylester-polyrotaxanes as a new calcium chelating polymer: synthesis, calcium binding and mechanism of trypsin inhibition. Int. J. Pharm. 242, 47-54 (2002).

86 Matsuura, K., Watanabe, K., Matsushita, Y. \& Kimizuka, N. Guest-binding behavior of peptide nanocapsules self-assembled from viral peptide fragments. Polym. J. 45, 529-534 (2013).

87 Sofos, M., Goldberger, J., Stone, D. A., Allen, J. E., Ma, Q., Herman, D. J., Tsai, W. W., Lauhon, L. J. \& Stupp, S. I. A synergistic assembly of nanoscale lamellar photoconductor hybrids. Nat. Mater. 8, 68-75 (2009).

88 Lee, K., Wagermaier, W., Masic, A., Kommareddy, K.P., Bennet, M., Manjubala, I., Lee, S.-W., Park, S.B., Cölfen, H. \& Fratzl, P. Self-assembly of amorphous calcium carbonate microlens arrays. Nat. Commun. 3, 725 (2012).

89 Matsunaga, T., Suzuki, T., Tanaka, M. \& Arakaki, A. Molecular analysis of magnetotactic bacteria and development of functional bacterial magnetic particles for nano-biotechnology. Trends Biotechnol. 25, 182-188 (2007).

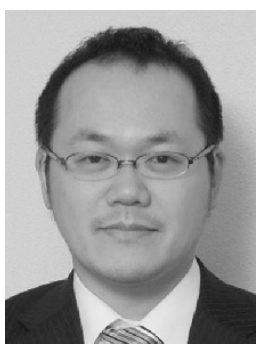

Tatsuya Nishimura is an Assistant Professor of Department of Chemistry and Biotechnology at the University of Tokyo. He received his $\mathrm{PhD}$ from Nagoya University in 2004 under the supervision of Professor Eiji Yashima. After his postdoctoral researches at the University of Tokyo with Professor Takashi Kato (2004-2005) as a JSPS postdoctoral fellow, he joined the University of Tokyo. His studies include the synthesis and orientational controls of novel organic/inorganic hybrids by using macromolecular templates through approaches inspired by biomineralization. He received the Award for Encouragement of Research in Polymer Science from the Society of Polymer Science, Japan (2012). 